\title{
A solitary fibrous tumor mimicking a peripheral nerve sheath tumor: Case report and review of the literature
}

\author{
Frederick L Hitti ${ }^{1 *}$, Jeremy E Adler ${ }^{2}$, Ming Zhang ${ }^{2}$, Matt L Kirkland ${ }^{3}$ and William C Welch ${ }^{1}$ \\ ${ }^{1}$ Department of Neurosurgery, Pennsylvania Hospital, University of Pennsylvania, 800 Spruce St, Philadelphia, PA 19107, USA \\ ${ }^{2}$ Department of Pathology, Pennsylvania Hospital, University of Pennsylvania, 800 Spruce St, Philadelphia, PA 19107, USA \\ ${ }^{3}$ Department of Surgery, Pennsylvania Hospital, University of Pennsylvania, 800 Spruce St, Philadelphia, PA 19107, USA
}

\begin{abstract} was made. of tissue diagnosis and complete resection for treatment.

\section{Introduction}

Solitary fibrous tumors (SFT) may be found in many locations including the thorax, CNS, and abdomen/pelvis [1-3]. Non-invasive imaging is generally used for initial diagnosis of mass lesions. We present the case of a mass intimately associated with the S1 nerve that was initially diagnosed as a peripheral nerve sheath tumor on imaging. Permanent pathology, however, revealed a SFT. Fewer than 5 cases of SFT in locations associated with peripheral nerves or nerve roots have been documented [4-7]. Here, we present the case of a woman that presented with symptoms of S1 nerve compression and was found to have a mass associated with the S1 nerve that was eventually diagnosed as a SFT.
\end{abstract}

Background: Solitary fibrous tumors (SFT) are commonly found in the thorax, however extrathoracic locations may present with symptoms of nerve compression.

Case description: The patient is a 38-year-old woman with two years of back pain, right lower quadrant abdominal pain, and right buttock pain. Imaging showed an enhancing, cystic mass in the right upper pelvis continuous with the S1 nerve root suspicious for nerve sheath tumor. The mass was resected and a diagnosis of SFT

Conclusions: While the patient's mass was initially thought to be a peripheral nerve sheath tumor, pathology revealed that it was a SFT. We highlight the importance

Key messages: While rare, solitary fibrous tumors can be found in extrathoracic sites including abutting the S1 nerve root. Imaging suggested peripheral nerve sheath tumor, however permanent pathology revealed a solitary fibrous tumor. We highlight the importance of tissue diagnosis and complete resection for treatment.

\section{Case history}

The patient is a 38-year-old woman who presented with a twoyear history of back pain, right lower quadrant abdominal pain, and right buttock pain. Her medical history was unremarkable and surgical history included benign uterine polyp removal. Computed tomography (CT) of the abdomen/pelvis without contrast that demonstrated a 3.7 x $2.9 \times 4.1 \mathrm{~cm}$ cystic lesion in the right posterior lateral pelvis (Figure 1). Of note, the patient had a prior CT of the abdomen/pelvis done 8 years earlier for abdominal pain that did not show the lesion. Magnetic resonance imaging (MRI) of the pelvis with contrast demonstrated that the multi-loculated, enhancing, cystic mass in the right upper pelvis was separate from the right ovary and contiguous with the R S1 nerve root (Figure 1). At this time, a diagnosis of cystic peripheral nerve sheath tumor was favored. She was referred to our office for further evaluation.

On exam, the patient had reduced sensation to pin prick in the right leg in the S1 nerve root distribution. Her reflexes were $1+$ in the bilateral lower extremities and $3+$ in the bilateral upper extremities.
Otherwise, her neurological examination, including lower extremity strength, was normal.

We recommended surgical biopsy and resection via a transperitoneal laparoscopic approach. The tumor was found inferior to the right iliac vessels. The S1 nerve root appeared to be entering the superior aspect of the tumor. Branches of the internal iliac artery supplying the lesion were then ligated, the peritoneum transected, and the anterior surface of the tumor was exposed.

No motor responses were noted upon stimulation of the anterior surface of the tumor, so the anterior surface was opened and the cystic contents were drained. A cupped forceps was used to evacuate the solid contents of the tumor. The entire course of the S1 nerve was identified to its exit from the foramen, and a gross total resection was achieved.

Final pathology showed sheets of lesional cells with oval to spindled nuclei and focal clear/foamy cytoplasm in the background of delicate vasculature. No necrosis was identified. Focal increased mitotic activity was seen- up to 8 per high-power field (HPF). Immunohistochemical (IHC) staining was performed with adequate controls for further evaluation of the specimen. The tumor cells were positive for CD34, STAT6, nuclear staining of CD117, and focally positive for Vimentin (Figure 2). The tumor cells were negative for AE1/3, PanCK, inhibin, calretinin, RCC, Synaptophysin, chromogranin, SOX10, S100, HMB45,

*Correspondence to: Frederick L. Hitti, Hospital of the University of Pennsylvania, $3^{\text {rd }}$ Floor Silverstein, 3400 Spruce St, Philadelphia, PA 19104, USA, Tel: 215-8340444; Fax: 215-349-5534; E-mail: Frederick.Hitti@uphs.upenn.edu

Key words: solitary fibrous tumor, peripheral nerve sheath tumor, mimic

Received: July 03, 2018; Accepted: July 20, 2018; Published: July 24, 2018 


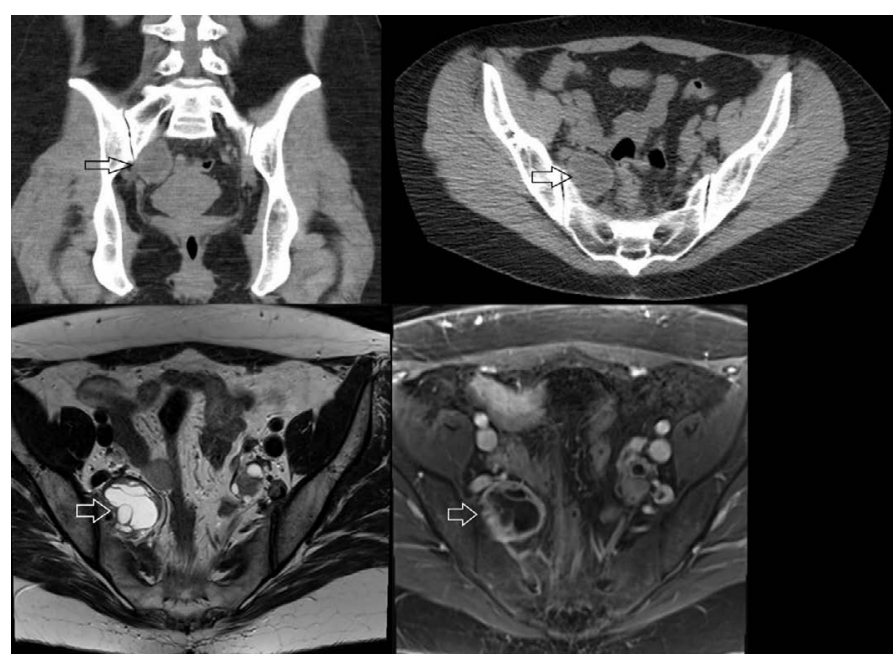

Figure 1. Pre-operative CT (top) and MR (bottom) imaging. Coronal (top left) and axial (top right) CT imaging of the lesion. The lesion, marked with an open arrow, had a hypodense center consistent with a cystic mass. T2 axial (bottom left) and T1 post-contrast (bottom right) MRI demonstrating the multi-loculated structure and contrast-enhancing rim of the lesion

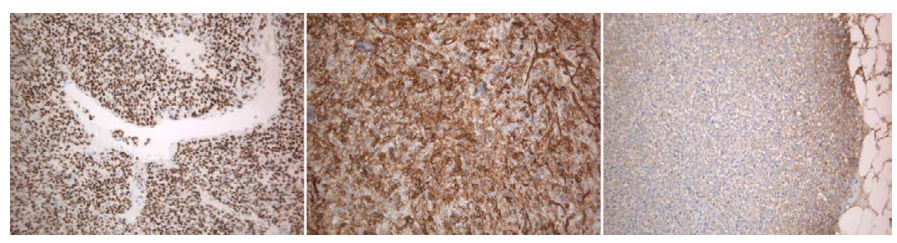

Figure 2. Tissue diagnosis. Immunohistochemistry was used to determine the expression of STAT6 (left), CD34 (middle), and vimentin (right). The specimen was positive for all three markers and supported a diagnosis of solitary fibrous tumor

SMA, GFAP, desmin, PAX8, PLAP, DOG-1, SALL4, OCT3/4 and EMA. Furthermore, the Ki-67 index was approximately $15 \%$.

Given the aforementioned histological and immunohistochemical findings, a diagnosis of solitary fibrous tumor (SFT) was made. A recently developed four-variable risk stratification model for development of metastasis in solitary fibrous tumors was used to guide prognosis. Given a patient age of $<55$, tumor size of $<5 \mathrm{~cm}$, mitotic count $>4 / \mathrm{HPF}$, and $<10 \%$ tumor necrosis a total score of $2 / 7$ was obtained. The tumor was therefore classified as low risk for development of metastasis. This modified four-variable model (tumor necrosis added as a fourth variable) has been demonstrated to enhance predictive power $[8,9]$.

\section{Discussion}

Due to its close its intimate association with the S1 nerve, this lesion was initially favored to be a peripheral nerve sheath tumor. Permanent pathology, however, demonstrated that the lesion was, in fact, a SFT. These tumors are fibroblastic mesenchymal neoplasms that typically do not metastasize [8-11]. These lesions may arise in a variety of locations including the thorax, CNS, and abdomen/pelvis [1-3]. They are more commonly found in the soft tissues but may also be found in the viscera [3]. Historically, SFTs were considered separate from hemangiopericytomas [12]. Refinement of IHC and genetic testing, including evaluation for the NAB2-STAT6 gene fusion, demonstrated that SFTs and hemangiopericytomas shared overlapping features [13]. SFT is currently the preferred terminology for these tumors.

SFTs may initially be diagnosed with CT or MR imaging, however investigation of the tissue histologically is required for diagnosis.
Cellularity of these tumors varies. Hypocellular tumors typically appear as spindled cells in a stroma of dense collagen [14]. Hypercellular tumors do not have a dense collagen background. Instead, nests of rounded/ ovoid cells are found with sparse collagen, prominent capillaries, and occasionally necrosis [14]. In this case, the tumor sample had a mixture of both characteristics. IHC may be used to support the histological diagnosis. STAT6 staining is often positive in SFTs, as it was in this case [15-17]. Other markers include CD34 and vimentin, which were both positive in this case. The tumor cells must also be negative for EMA, S100, and desmin, as was also true in this case [15-17].

Due to its intimate association with the $\mathrm{S} 1$ nerve, we favored peripheral nerve sheath tumor as our pre-operative diagnosis based on the CT and MR imaging. Based on its location in the pelvis other diagnoses included ovarian tumor, fibroma, or uterine leiomyoma. These diagnoses were less favored given the patient's symptoms and imaging characteristics.

Surgical resection is the mainstay of treatment for SFTs, including extrathoracic SFTs [2,18-20]. Overall, 5-year survival is $84 \%$ and local recurrence and rate of metastasis are $29 \%$ and $34 \%$ respectively [2]. While there is evidence for increased rates of recurrence of extrathoracic SFTs after surgical resection, it remains the preferred treatment [20]. There is generally little role for radiation therapy in the treatment of SFTs, however there are case reports of radiation treatment for recurrent or incompletely resected SFTs [21,22]. Similarly, chemotherapy has a limited role in treatment of SFTs. Studies have shown mixed results with anthracycline-based chemotherapy and it is not generally recommended $[23,24]$. However, newer biological agents such as temozolomide, bevacizumab, and sunitinib have showed some promise in the treatment of recurrent or malignant SFTs $[25,26]$.

\section{Conclusions}

While rare, solitary fibrous tumors can be found in extrathoracic sites such as the pelvis. In this report, we review the case of a patient who presented with signs and symptoms attributable to S1 nerve root compression with imaging demonstrating a mass abutting the S1 nerve root. It was initially thought to be a peripheral nerve sheath tumor, however permanent pathology revealed that it was a SFT. We highlight the importance of tissue diagnosis and complete resection for treatment. Safe surgical treatment involves a multi-disciplinary team of general and neurological surgeons.

\section{References}

1. Brunnemann RB, Ro JY, Ordonez NG, Mooney J, El-Naggar AK, et al. (1999) Extrapleural solitary fibrous tumor: a clinicopathologic study of 24 cases. Mod Pathol 12: 1034-1042. [Crossref]

2. Van Houdt WJ, Westerveld CM, Vrijenhoek JE, van Gorp J, van Coevorden F, et al (2013) Prognosis of solitary fibrous tumors: a multicenter study. Ann Surg Oncol 20: 4090-4095. [Crossref]

3. Moran CA, Ishak KG, Goodman ZD (1998) Solitary fibrous tumor of the liver: a clinicopathologic and immunohistochemical study of nine cases. Ann Diagn Pathol 2: 19-24. [Crossref]

4. Kataoka H, Akiyama Y, Kubo S, Itoh H, Hamasuna R, et al. (1999) Solitary fibrou tumor of the spinal nerve rootlet: case report and literature survey. Pathol Int 49: 826830. [Crossref]

5. Nagano A, Ohno T, Nishimoto Y, Oshima K, Shimizu K (2014) Malignant solitary fibrous tumor of the lumbar spinal root mimicking schwannoma: a case report. Spine $J$ 14: e17-20. [Crossref]

6. Pedro MT, Antoniadis G, Scheuerle A, Pham M, Wirtz CR, et al. (2015) Intraoperative high-resolution ultrasound and contrast-enhanced ultrasound of peripheral nerve tumors and tumorlike lesions. Neurosurg Focus 39: E5. [Crossref] 
7. Piana S, Putrino I, Cavazza A, Nigrisoli E (2004) Solitary fibrous tumor of the spinal nerve rootlet: report of a case mimicking schwannoma. Arch Pathol Lab Med 128: 335-337. [Crossref]

8. Demicco EG, Park MS, Araujo DM, Fox PS, Bassett RL, et al. (2012) Solitary fibrous tumor: a clinicopathological study of 110 cases and proposed risk assessment model. Mod Pathol 25: 1298-1306. [Crossref]

9. Demicco EG, Wagner MJ, Maki RG, Gupta V, et al. (2017) Risk assessment in solitary fibrous tumors: validation and refinement of a risk stratification model. Mod Pathol 30: 1433-1442. [Crossref]

10. Ali SZ, Hoon V, Hoda S, Heelan R, Zakowski MF (1997) Solitary fibrous tumor. A cytologic-histologic study with clinical, radiologic, and immunohistochemical correlations. Cancer 81: 116-121. [Crossref]

11. Gronchi A, Miceli R, Allard MA, Callegaro D, Le Péchoux C, et al. (2015) Personalizing the approach to retroperitoneal soft tissue sarcoma: histology-specific patterns of failure and postrelapse outcome after primary extended resection. Ann Surg Oncol 22: 1447-1454. [Crossref]

12. Stout AP, Murray MR (1942) Hemangiopericytoma: a vascular tumor featuring zimmermann's pericytes. Ann Surg 116: 26-33. [Crossref]

13. Barthelmeß S, Geddert H, Boltze C, Moskalev EA, Bieg M, et al. (2014) Solitary fibrous tumors/hemangiopericytomas with different variants of the NAB2-STAT6 gene fusion are characterized by specific histomorphology and distinct clinicopathological features. Am J Pathol 184: 1209-1218. [Crossref]

14. Hanau CA, Miettinen M (1995) Solitary fibrous tumor: Histological and immunohistochemical spectrum of benign and malignant variants presenting at different sites. Hum Pathol 26: 440-449. [Crossref]

15. Demicco EG, Harms PW, Patel RM, Smith SC, Ingram D, et al. (2015) Extensive survey of STAT6 expression in a large series of mesenchymal tumors. Am J Clin Pathol 143: 672-682. [Crossref]

16. Doyle LA, Vivero M, Fletcher CD, Mertens F, Hornick JL (2014) Nuclear expression of STAT6 distinguishes solitary fibrous tumor from histologic mimics. Mod Pathol 27: 390-395. [Crossref]
17. Yoshida A, Tsuta K, Ohno M, Yoshida M, Narita Y, et al. (2014) STAT6 immunohistochemistry is helpful in the diagnosis of solitary fibrous tumors. Am J Surg Pathol 38: 552-559. [Crossref]

18. Kayani B, Sharma A, Sewell MD, Platinum J, Olivier A, et al. (2018) A Review of the Surgical Management of Extrathoracic Solitary Fibrous Tumors. Am J Clin Oncol 41 687-694. [Crossref]

19. Wang H, Chen P, Zhao W, Shi L, Gu X, et al. (2014) Clinicopathological findings in a case series of abdominopelvic solitary fibrous tumors. Oncol Lett 7: 1067-1072. [Crossref]

20. Wilky BA, Montgomery EA, Guzzetta AA, Ahuja N, Meyer CF (2013) Extrathoracic location and "borderline" histology is associated with recurrence of solitary fibrous tumors after surgical resection. Ann Surg Oncol 20: 4080-4089. [Crossref]

21. Gao C, Zhang Y, Jing M, Qu W, Li J, et al. (2016) Postoperative Radiotherapy for the Treatment of Solitary Fibrous Tumor With Malignant Transformation of the Pelvic: A Rare Case Report With Literature Review. Medicine (Baltimore) 95: e2433. [Crossref]

22. Gao C, Zhang Y, Li Y-Y, Yu Y-H, Qu W, et al. (2015) Postoperative recurrence solitary fibrous tumor of the pelvic with malignant transformation. Int J Clin Exp Med 8 : 16827-16833. [Crossref]

23. Constantinidou A, Jones RL, Olmos D, Thway K, Fisher C, Al-Muderis O, et al Conventional anthracycline-based chemotherapy has limited efficacy in solitary fibrous tumour. Acta Oncol. Stockh. Swed. 2012; 51:550-554. [Crossref]

24. Stacchiotti S, Libertini M, Negri T, Palassini E, Gronchi A, et al. (2013) Response to chemotherapy of solitary fibrous tumour: a retrospective study. Eur J Cancer 49 : 2376-2383. [Crossref]

25. Park MS, Patel SR, Ludwig JA, Trent JC, Conrad CA, et al. (2011) Activity of temozolomide and bevacizumab in the treatment of locally advanced, recurrent, and metastatic hemangiopericytoma and malignant solitary fibrous tumor. Cancer 117: 4939-4947. [Crossref]

26. Stacchiotti S, Negri T, Libertini M, Palassini E, Marrari A, et al. (2012) Sunitinib malate in solitary fibrous tumor (SFT). Ann Oncol 23: 3171-3179. [Crossref]

Copyright: C2018 Hitti FL. This is an open-access article distributed under the terms of the Creative Commons Attribution License, which permits unrestricted use, distribution, and reproduction in any medium, provided the original author and source are credited. 